\title{
Cryptococcus neoformans var. grubii - Pathogenicity of environmental isolates correlated to virulence factors, susceptibility to fluconazole and molecular profile
}

\author{
Reginaldo S Pedroso ${ }^{1,2} /{ }^{+}$, Marco AS Lavrador ${ }^{2}$, Joseane C Ferreira ${ }^{2}$, \\ Regina C Candido², Claudia ML Maffei ${ }^{3}$ \\ 'Escola Técnica de Saúde, Universidade Federal de Uberlândia, Av. Amazonas s/n bloco 4K, 38400-902 Uberlândia, MG, Brasil \\ ${ }^{2}$ Faculdade de Ciências Farmacêuticas de Ribeirão Preto \\ ${ }^{3}$ Faculdade de Medicina de Ribeirão Preto, Universidade de São Paulo, Ribeirão Preto, SP, Brasil
}

The pathogenicity of Cryptococcus neoformans is heterogeneous and is associated with the expression of virulence factors. This study aimed to correlate the pathogenicity of $\mathrm{C}$. neoformans var. grubii in BALB/c mice with in vitro virulence factors, fluconazole minimal inhibitory concentrations (MICs) and molecular profiles, before and after animal passage. Ten environmental isolates and one ATCC strain of C. neoformans var. grubii mating type $\alpha$ were evaluated. Most isolates (91\%) killed 50\% or more of the infected animals by day 24 postinfection and were recovered from the lungs and brains of surviving animals on days 7 and 14 postinfection. The burden of yeast in the lungs was more variable than that in the brain. The differences in the expression of virulence factors (growth at $37^{\circ} \mathrm{C}$, presence and size of the capsule and production of melanin, urease, proteinase and phospholipase) by most isolates pre and postpassage in animals were not statistically significant. The fluconazole MICs in postpassaged lines differed by a one-dilution from the MIC of the corresponding prepassaged line for six isolates. Using molecular typing [polymerase chain reaction-fingerprinting with (GACA) ${ }_{4}$ and M13], eight isolates were identified as VNI and three as VNII. We concluded that different isolates with the same molecular and phenotypic profiles, including isolates that are markedly hypervirulent, span a wide range of virulence and there were no changes in virulence factors in the postpassaged lines when compared with the corresponding nonpassaged lines.

Key words: Cryptococcus neoformans - virulence factors - pathogenicity - molecular typing

Cryptococcus neoformans, an opportunistic fungus, is responsible for infections in immunocompromised hosts and three serotypes have been recognised: A (var. grubii), D (var. neoformans) and the hybrid AD. $C$. neoformans has well-defined mating types, constituted by one locus with two alternative alleles, mating type a and mating type $\alpha$ (Casadevall \& Perfect 1998, Campbell \& Carter 2006). Clinical and environmental isolates of $C$. neoformans are mostly of mating type $\alpha$ (Okabayashi et al. 2006).

Genetic differences between serotypes and among different isolates, both clinical and environmental, have been shown by phenotypic, immunological and, more recently, molecular typing methods. Techniques based on polymerase chain reaction (PCR) have been used to study the epidemiology of $C$. neoformans. PCR-based methods are more sensitive, specific and fast and are less likely to be influenced by external factors than traditional methods based on phenotypic characteristics (Meyer et al. 1993). By applying molecular techniques, it was

Financial support: $\mathrm{CNPq}$

+ Corresponding author: rpedroso@estes.ufu.br

Received 23 April 2010

Accepted 27 October 2010 possible to group $C$. neoformans into at least four molecular types: VNI and VNII (both var. grubii, serotype A), VNIII (serotype AD) and VNIV (var. neoformans, serotype D), according to Meyer et al. (2003). The molecular type VNI, followed by VNII, has predominated in clinical and environmental isolates in the central regions of Brazil, especially in the South, Southeast and Central Regions (Trilles et al. 2008).

C. neoformans pathogenicity is related to virulence factors including the presence and size of the polysaccharide capsule, the production of melanin by laccase, growth at $37^{\circ} \mathrm{C}$ and secretion of the enzymes phospholipase, proteinase and urease (Kozel 1995, Casadevall \& Perfect 1998). Studies on pathogenicity and on these virulence factors are fundamental to the understanding of the pathogenesis and biology of $C$. neoformans. Some of these virulence factors have been used in phenotypic typing (Kozel 1995, Idnurm et al. 2005).

It has been shown that the phenotypic characteristics of $C$. neoformans may be related to virulence and its susceptibility to antifungal drugs may change in cases of recurrent infection in immunocompromised patients, after experimental inoculation in animals and after long in vitro storage periods (Currie et al. 1995, Franzot et al. 1998, Blasi et al. 2001, McClelland et al. 2005, Clancy et al. 2006, Silva et al. 2006b). This phenomenon, called microevolution, has been reported by several authors (Franzot et al. 1998, Blasi et al. 2001, Almeida et al. 2007, Cavalcante et al. 2007). 
C. neoformans can cause life-threatening fungal infections in immunocompromised individuals. The source of infection is the environment and there are some phenotypic and genotypic differences among isolates. Thus, this study aims to correlate pathogenicity and (i) virulence factors, (ii) the fluconazole minimal inhibitory concentration (MIC) and (iii) the molecular profiles obtained by PCR-fingerprinting in pre and postpassaged lines of environmental isolates of $C$. neoformans var. grubii from the city of Ribeirão Preto, state of São Paulo (SP), Brazil. In addition, we analyzed whether there were temporal differences in the parasite burden in the lungs and brains of animals at seven and 14 days after infection.

\section{SUBJECTS, MATERIALS AND METHODS}

Microorganisms - Ten environmental isolates of C. neoformans from bird excreta collected in Ribeirão Preto (Pedroso et al. 2009a) and the strain ATCC 90112 (var. grubii, mating type $\alpha$ ) were analyzed in this study. Identification was conducted by classical methods based on urease production, the presence of a capsule, melanin production in L-dopa medium, the assimilation of nitrogen and carbon sources and the canavanine-glycine-bromothymol blue test. All identifications were confirmed using the ID32C system (bioMérieux AS, Marcy l'Etoile, France) and by DNA amplification using a species-specific forward primer CN-ITS1 (5'-TGGACTTTGGTCCATTTATCTAC-3') for the internal transcribed spacer (ITS) 1 and a universal reverse primer ITS4 (5'-TCCTCCGCTTATTGATATGC-3'), according to Li et al. (2003). Isolates were incubated at $25-30^{\circ} \mathrm{C}$ in Sabouraud dextrose agar (SDA) and subcultured bimonthly.

Determination of serotype and mating type-Genomic DNA was extracted as described by Bolano et al. (2001) with some modifications (Pedroso et al. 2009b) and the extracted DNA was maintained at $-20^{\circ} \mathrm{C}$ until use. Serotypes and mating types were determined using PCR with the primers described in Table I. Amplification reactions were performed in a final volume of $50 \mu \mathrm{L}$ containing 60 ng genomic DNA, 1 x PCR buffer (Fermentas, Ontario, CA), $1.5 \mathrm{mM}$ magnesium chloride, $0.2 \mathrm{mM}$ each
dNTP, 21 pmol of each primer and $1 \mathrm{U}$ Taq polymerase (Fermentas, Ontario, CA). Reaction conditions were as follows: initial denaturation at $94^{\circ} \mathrm{C}$ for $10 \mathrm{~min}, 36$ cycles at $94^{\circ} \mathrm{C}$ for $1 \mathrm{~min}$, annealing according to the temperature specified in Table I for $1 \mathrm{~min}$, and extension at $72^{\circ} \mathrm{C}$ for $1 \mathrm{~min}$, and a $10-\mathrm{min}$ final extension at $72^{\circ} \mathrm{C}$. Amplification products were maintained at $4^{\circ} \mathrm{C}$ and then submitted to $1 \%$ agarose gel electrophoresis in $1 \mathrm{x}$ tris-acetate (TAE)-ethylenediamine tetraacetic acid buffer at $75 \mathrm{~V}$ for $2 \mathrm{~h}$. For each reaction, a known strain was used as a positive control. DNA fragments were observed under UV light in an ethidium bromide-stained gel, which was photographed using an image capturing system.

Experimental infection - Experiments were conducted according to the Ethical Principles in Animal Experimentation and were approved by the Committee on Ethics in Animal Use of the University of São Paulo, Ribeirão Preto Campus (protocol 05.1.327.53.7).

Female isogenic BALB/c mice, weighing $20 \mathrm{~g}$, were utilized for the experimental infections. Microorganisms from recent cultures $\left(72 \mathrm{~h}\right.$ at $35^{\circ} \mathrm{C}$ in SDA) were transferred to culture tubes containing $20 \mathrm{~mL}$ of brain heart infusion broth and incubated under constant agitation $(200 \mathrm{rpm})$ at $35^{\circ} \mathrm{C}$ for $48 \mathrm{~h}$. Cells were separated by centrifugation $(5,000 \mathrm{~g}$ for $5 \mathrm{~min})$, washed three times with sterile physiological solution and adjusted to a concentration of $5 \times 10^{6}$ cells/mL. Mice were inoculated with $100 \mu \mathrm{L}$ of cell suspension $\left(5 \times 10^{5}\right.$ cells) through the lateral vein in the tail. Each isolate preparation was used to inoculate nine animals (for a total of 11 groups of 9 animals each), of which five were observed daily for the development of infection and death. Two animals were euthanized by cervical dislocation on day seven and two on day 14. The brain and lungs were removed for determination of the number of colony forming units (CFUs). The removed organs were weighed and homogenized in a T18 basic Ultra Turrax Mixer (IKA, Wilmington, NC, USA) at 18,000 rpm for $30 \mathrm{~s}$. Thereafter, serial dilutions to $10^{-1}, 10^{-2}, 10^{-3}$ and $10^{-4}$ were prepared and aliquots of $100 \mu \mathrm{L}$ of each dilution were plated on SDA-chloramphenicol and incubated at $37^{\circ} \mathrm{C}$ for $72 \mathrm{~h}$. The results are expressed as mean of $\log _{10} \mathrm{CFU} / \mathrm{g}$ of each organ.

TABLE I

Nucleotide pairs and annealing temperatures employed in serotype and mating type determinations

\begin{tabular}{|c|c|c|c|c|}
\hline Serotype and/or mating & $\begin{array}{c}\text { Sequences } \\
\text { (forward and reverse) }\end{array}$ & $\begin{array}{l}\text { Annealing temperature } \\
\qquad\left({ }^{\circ} \mathrm{C}\right)\end{array}$ & $\begin{array}{l}\text { Product } \\
\text { (bp) }\end{array}$ & References \\
\hline A $M A T \alpha$ & $\begin{array}{l}\text { 5'-GCTTGGCGTACGCTGTGG-3' } \\
\text { 5'-GGCGTCGCTTGGTACGGGT-3' }\end{array}$ & 60 & 1,150 & Figueiredo (2007) \\
\hline $\mathrm{A} M A T \mathrm{a}$ & $\begin{array}{c}\text { 5'-TCCACTGGCAACCCTGCGGAG-3' } \\
\text { 5'-ATCAGAGACAGAGAAGCAAGAC-3' }\end{array}$ & 55 & 865 & Okabayashi et al. (2006) \\
\hline $\mathrm{D} M A T \alpha$ & $\begin{array}{l}\text { 5'-GATTATCTCAGCAGCCACG-3' } \\
\text { 5'-AAATCGGCTACGGCACGTC-3' }\end{array}$ & 60 & 443 & Okabayashi et al. (2006) \\
\hline $\mathrm{D} M A T \mathrm{a}$ & $\begin{array}{l}\text { 5'-GGTCCGCACTTGGGTAAGTG-3' } \\
\text { 5'-GGCGTAGACGGACGAGCTC-3' }\end{array}$ & 60 & 1,420 & Figueiredo (2007) \\
\hline
\end{tabular}

bp: base pairs. 
Evaluation of the virulence factors - Virulence factors were analyzed in pre and postpassaged lines in mice. Capsule production and thickness was determined according to the method of Pedroso et al. (2009b) using liquid Sabouraud medium containing $0.1 \%$ glucose. The results are expressed as scores: 0 for isolates without visible capsules, 1 for isolates with a small amount of visible capsule, 2 for isolates with a moderate amount of capsule (cell diameter plus capsule smaller than twice the cell diameter) and 3 for isolates with large capsules (cell diameter plus capsule equal to or larger than twice the cell diameter). Tests were scored by the same methods in both conditions.

Growth at $37^{\circ} \mathrm{C}$ was measured according to the method of Pedroso et al. (2009b) and the results are expressed as scores: 0 , no growth, 1 , poor growth (few isolated colonies), 2 , moderate growth (confluent colonies but smaller than the control colonies) and 3, growth equivalent to the control incubated at $30^{\circ} \mathrm{C}$.

Plates containing L-dopa medium $(1.5 \%$ agar, $15 \mathrm{mM}$ glucose, $10 \mathrm{mM} \mathrm{MgSO}$, $29.4 \mathrm{mM} \mathrm{KH}_{2} \mathrm{PO}_{4}, 13 \mathrm{mM}$ glycine, $3.0 \mu \mathrm{M}$ thiamine and $1.0 \mathrm{mM} \mathrm{L}$-dopa) were used to measure the production of melanin after incubation at $30^{\circ} \mathrm{C}$ for five days. Pigment intensity was recorded after grouping the isolates with equally coloured colonies according to the following scoring system: 0 for colonies without pigment, 1 for light brown colonies, 2 for brown colonies, 3 for dark brown colonies and 4 for black colonies.
Urease activity was determined by adding $100 \mu \mathrm{L}$ of cell suspension (equivalent to McFarland scale 2) to $500 \mu \mathrm{L}$ of urea liquid medium (Christensen urea). After 24 and $48 \mathrm{~h}$ of incubation, the activity was scored as follows: 0 for no colour (absence of activity), 1 for light pink colour, 2 for moderate pink colour and 3 for intense pink colour. Proteinase activity was detected on agar plates containing albumin that had been incubated at $30^{\circ} \mathrm{C}$ for 14 days (Aoki et al. 1994). Plates containing egg-yolk agar were used to detect phospholipase activity after incubation at $30^{\circ} \mathrm{C}$ for seven days (Echeverría et al. 2002). An opaque zone (phospholipase activity) or a dense white zone of hydrolysis (proteinase activity) around a yeast colony was expressed as $\mathrm{Pz}=\mathrm{cd} / \mathrm{cdp}$, where cd is the colony diameter and cdp is the colony diameter plus the precipitation zone.

Susceptibility to fluconazole - The methodology followed recommendations of the M27-A2 document of CLSI/NCCLS (2002). Susceptibility was visually determined by comparing the turbidity of the fluconazole-treated cultures with the turbidity of a control culture. The MIC of fluconazole was defined as the concentration producing $50 \%$ inhibition. Strains of Candida parapsilosis ATCC 22019 and Candida krusei ATCC 6258 were used controls.

\section{TABLE II}

Cumulative percentage of dead animals $(n=5)$ at the indicated days after inoculation of environmental samples of Cryptococcus neoformans

\begin{tabular}{|c|c|c|c|c|c|c|c|c|c|c|c|}
\hline \multirow{2}{*}{$\begin{array}{l}\text { Time } \\
\text { (days after infection) }\end{array}$} & \multicolumn{11}{|c|}{ Cumulative } \\
\hline & CN13 & CN17 & CN18 & CN19 & CN20 & CN22 & $\mathrm{CN} 23$ & CN24 & $\mathrm{CN} 25$ & CN26 & 90112 \\
\hline 10 & - & 20 & - & - & - & - & - & - & - & - & - \\
\hline 11 & - & 40 & - & - & - & - & - & - & - & - & - \\
\hline 12 & - & 100 & - & - & - & - & 20 & - & - & - & - \\
\hline 14 & - & - & - & - & 20 & - & - & - & - & - & - \\
\hline 15 & 20 & - & - & - & 40 & - & - & - & - & - & 20 \\
\hline 16 & 60 & - & 20 & - & 60 & 20 & - & - & 20 & - & - \\
\hline 17 & 80 & - & - & - & 80 & - & 40 & - & 40 & - & 40 \\
\hline 18 & 100 & - & 40 & - & - & - & - & 20 & 60 & - & 60 \\
\hline 19 & - & - & - & - & - & - & 60 & 40 & 80 & 20 & 100 \\
\hline 20 & - & - & - & - & 100 & - & - & 80 & 100 & 40 & - \\
\hline 21 & - & - & - & - & - & 40 & 80 & - & - & - & - \\
\hline 22 & - & - & - & - & - & 60 & 100 & - & - & - & - \\
\hline 23 & - & - & - & - & - & 80 & - & - & - & 60 & - \\
\hline 24 & - & - & 60 & - & - & 100 & - & 100 & - & 80 & - \\
\hline 25 & - & - & 80 & - & - & - & - & - & - & - & - \\
\hline 28 & - & - & 100 & - & - & - & - & - & - & - & - \\
\hline 33 & - & - & - & - & - & - & - & - & - & 100 & - \\
\hline 40 & - & - & - & 20 & - & - & - & - & - & - & - \\
\hline 62 & - & - & - & 40 & - & - & - & - & - & - & - \\
\hline 72 & - & - & - & 60 & - & - & - & - & - & - & - \\
\hline 79 & - & - & - & 80 & - & - & - & - & - & - & - \\
\hline 82 & - & - & - & 100 & - & - & - & - & - & - & - \\
\hline
\end{tabular}

-: no animal dead in this time. 
Molecular typing by PCR-fingerprinting - Molecular typing was completed according to the method of Meyer and Mitchell (1995) and Meyer et al. (2003) based on fragment amplification by PCR using only minisatellite sequences of the M13 phage (5'GAGGGTGGCGGTTCT-3') and repetitive microsatellite sequences (GACA) ${ }_{4}$ as probes. The final reaction volume was $50 \mu \mathrm{L}$ and each reaction contained $200 \mathrm{ng}$ DNA, 1 x enzyme buffer (Invitrogen, CA, USA), 60 pmol primer and 2.5 U Taq polymerase. The thermocycler conditions were as follows: $10 \mathrm{~min}$ at $94^{\circ} \mathrm{C}, 36$ cycles of $1 \mathrm{~min}$ at $94^{\circ} \mathrm{C}, 1 \mathrm{~min}$ at $50^{\circ} \mathrm{C}$ and $1 \mathrm{~min}$ at $72^{\circ} \mathrm{C}$ and a final extension of $10 \mathrm{~min}$ at $72^{\circ} \mathrm{C}$. Five microlitres of the amplified DNA sample were submitted to $1.5 \%$ agarose gel electrophoresis in $1 \times$ TAE containing $0.5 \mu \mathrm{g} / \mathrm{mL}$ ethidium bromide at $70 \mathrm{~V}$ for $3 \mathrm{~h}$. The gel was visualized by UV light and photographed using an image capturing system. The molecular types were assigned by comparison to the reference strains of each of the molecular types, VNI, VNII, VNIII and VNIV. The DNA of the reference strains H99, C12, ZG287 and NIH33 (types VNI, VNII, VNIII and VNIV, respectively) were kindly provided by Dr Joseph Heitman of Duke University Medical Center, USA (Figueiredo 2007). The molecular profiles obtained by PCR-fingerprinting were analyzed based on the presence or absence of clear and well-defined bands in the digitized gel images.

Statistical analysis - The yeast burden in animal organs was measured at two times, seven and 14 days postinfection (time $=$ factor), for each isolate (block); that is, we used an experimental structure consisting of completely randomized blocks (McPherson 1990) to test the effects of time and isolate on yeast burden in the lungs. Time ( 7 or 14 days) was considered one factor and the isolates were considered to be blocks. After significant effects of the isolates in the yeast burden were identified, the analysis was followed by the multiple comparison least significant difference test (LSD) to compare pairs of isolates (McPherson 1990). In all tests we used a significance level of $5 \%$.

The same procedures described were used to analyze the time and the isolate effects on yeast burden in the brain.

\section{RESULTS}

All isolates were serotype A and mating type $\alpha$ according to PCR conducted with the probes listed in Table I.

In the infection experiment, all isolates were recovered from mouse brain and lungs on seven or 14 day postinfection, with exception of CN17, which killed all animals by day 12 postinfection. Most animals ( $>50 \%$ ) in each group died within $12-72$ days and $91 \%$ of isolates killed $50 \%$ or more animals by day 24 postinfection (Table II).

The bar graphs in Fig. 1 show results for lungs and brains, in units of $\log _{10} \mathrm{CFU} / \mathrm{g}$, on days seven and 14 after inoculation with the $C$. neoformans isolates.

There was no significant difference between the burdens of microorganisms in the lungs on day seven and on day $14(p=0.086)$; however, there were significant differences $(p=0.008)$ in the microorganism burden among the isolates. Comparison of the isolates in pairs using the LSD test revealed the following differences: the burden of CN19 was different from those of CN13, CN20,
CN24, CN25, CN26 and 90112, the burden of CN18 was different from those of CN20, CN25, CN26 and 90112, the burden of CN20 was different from those of CN22 and CN23, the burden of CN22 was different from those of CN26 and 90112 and the burden of CN23 was different from those of CN25, CN26 and 90112.

When the same analysis was applied to brain data, the results showed a statistically significant difference in the burdens of yeast on days seven and 14 postinfection $(p=0.003)$ and among isolates $(p=0.002)$. The LSD test showed that the burden of CN19 was different from those of all other isolates and that the burden of CN18 was different from that of CN20. In both analyses, CN17 was not considered in the statistical tests because all animals died by day 12 after inoculation.

The results of the investigation of virulence factors and MICs for fluconazole are shown in Table III. All prepassaged lines grew at $37^{\circ} \mathrm{C}$ and produced capsules, melanin and phospholipase; only CN24 did not show urease activity by $24 \mathrm{~h}$. Most isolates $(54.5 \%)$ had proteinase activity. The fluconazole MICs were $4 \mu \mathrm{g} / \mathrm{mL}$ (CN13, CN17, CN18, CN19 and CN24), $8 \mu \mathrm{g} / \mathrm{mL}$ (CN20, CN22, CN23, CN25 and $\mathrm{CN} 26$ ) and $2 \mu \mathrm{g} / \mathrm{mL}$ for 90112 . The MIC values for the control strains were $2 \mu \mathrm{g} / \mathrm{mL}$ for $C$. parapsilosis ATCC 22019 (expected value, $1-4 \mu \mathrm{g} / \mathrm{mL}$ ) and $32 \mu \mathrm{g} / \mathrm{mL}$ for $C$. krusei ATCC 6258 (expected value, 16-128 $\mu \mathrm{g} / \mathrm{mL}$ ).

Most of the isolates were not significantly different from the prepassaged lines with respect to any studied virulence factor in vitro. After 24 h, CN24, which was negative for urease activity in prepassaged line, became
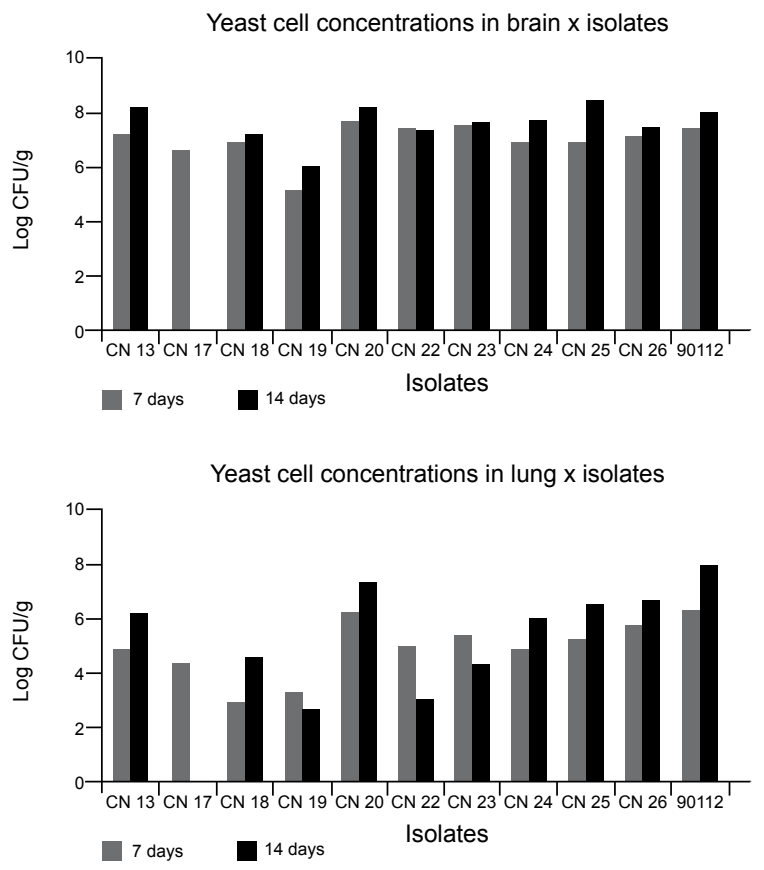

Fig. 1: concentration of viable yeast cells (log colony forming units/g) in lungs and brain of BALB/c mice, seven and 14 days after inoculation of a suspension containing $5 \times 10^{5}$ cells of different strains of Cryptococcus neoformans (CN). CFU: colony forming units. 
TABLE III

Cryptococcus neoformans $(\mathrm{CN})$ isolates characterized before and after inoculation in animals by virulence factors, fluconazole minimal inhibitory concentrations (MIC) and time of death of most animals

\begin{tabular}{|c|c|c|c|c|c|c|c|c|}
\hline Isolate & $\begin{array}{l}\text { Time } \\
\text { of death }^{a} \\
\text { (days) }^{\text {days }}\end{array}$ & $\begin{array}{c}\text { Growth at } \\
37^{\circ} \mathrm{C} \\
\text { (score) }\end{array}$ & $\begin{array}{c}\text { Capsule } \\
\text { (score) }\end{array}$ & $\begin{array}{l}\text { Urease } \\
(24 \mathrm{~h}) \\
\text { (score) }\end{array}$ & $\begin{array}{l}\text { Melanin } \\
\text { production } \\
\text { (score) }\end{array}$ & $\begin{array}{l}\text { Proteinase } \\
\quad(\mathrm{Pz})\end{array}$ & $\begin{array}{l}\text { Phospholi- } \\
\text { pase } \\
(\mathrm{Pz})\end{array}$ & $\begin{array}{c}\text { MIC } \\
\text { (fluconazol) } \\
\mu \mathrm{g} / \mathrm{mL}\end{array}$ \\
\hline CN13 & 16 & 3 & 2 & 3 & 3 & 0,91 & 0,74 & 4 \\
\hline CN17 & 12 & 3 & 1 & 3 & 4 & 1,00 & 0,83 & 4 \\
\hline CN18 & 24 & 3 & 3 & 3 & 4 & 1,00 & 0,59 & 4 \\
\hline CN19 & 72 & 3 & 2 & 3 & 4 & 0,85 & 0,69 & 4 \\
\hline CN20 & 16 & 3 & 2 & 3 & 3 & 0,90 & 0,89 & 8 \\
\hline CN22 & 22 & 3 & 2 & 3 & 3 & 0,83 & 0,79 & 8 \\
\hline $\mathrm{CN} 23$ & 19 & 3 & 2 & 1 & 4 & 1,00 & 0,60 & 8 \\
\hline CN24 & 20 & 3 & 3 & 0 & 4 & 0,87 & 0,67 & 4 \\
\hline CN25 & 18 & 2 & 1 & 2 & 3 & 1,00 & 0,71 & 8 \\
\hline CN26 & 23 & 3 & 2 & 3 & 3 & 0,83 & 0,67 & 8 \\
\hline 90112 & 18 & 3 & 3 & 3 & 4 & 1,00 & 0,55 & 2 \\
\hline
\end{tabular}

a: $60 \%$ of inoculated animals are dead; $\mathrm{Pz}=\mathrm{cd} / \mathrm{cdp}$, where $\mathrm{cd}$ is the colony diameter and cdp is the colony diameter plus the precipitation zone.

positive but with a score 1 . The fluconazole MIC changed by a one dilution for six isolates, CN24 $(2 \mu \mathrm{g} / \mathrm{mL}), \mathrm{CN} 22$, $\mathrm{CN} 23, \mathrm{CN} 25, \mathrm{CN} 26(4 \mu \mathrm{g} / \mathrm{mL})$ and $\mathrm{CN} 19(8 \mu \mathrm{g} / \mathrm{mL})$, when compared with the corresponding prepassaged lines.

PCR-fingerprinting allowed the isolates to be clustered into two molecular types, VNI (CN13, CN17, CN19 CN20, CN22, CN25 and CN26) and VNII (CN18, $\mathrm{CN} 23$ and CN24). Pre and postpassaged lines had identical electrophoretic band patterns, as shown in Figs 2, 3.

\section{DISCUSSION}

This study investigated the virulence of environmental isolates of $C$. neoformans var. grubii, mating type $\alpha$, in immunocompetent BALB/c mice and analyzed the phenotype of the primary virulence factors, the fluconazole MICs and the molecular profiles by PCR-fingerprinting. The tissue yeast burden was evaluated seven and 14 days postinfection. Brain isolates obtained on day seven were compared to prepassaged lines.

The yeast burden in the brain showed considerable temporal variation (from 7-14 days), while there was no such variation in the lungs. Nine isolates from the brains and seven from the lungs had higher CFU counts after 14 days of infection. Only CN22 had a lower count on day 14 than on day seven in the brain. CN19 can be considered the least virulent isolate as it had the lowest number of CFU in the brain and lungs after both periods of incubation.

The duration of the animals' survival was also highly variable. The isolate $\mathrm{CN} 17$ was the most virulent, killing all mice between 10-12 days postinfection, while CN19 was the least virulent, with all mice dying between 40 82 days. This result showed the great variability in the virulence among the studied isolates. The statistical analysis identified the isolates with different behaviours when considering the tissue yeast burden and the survival duration after infection. Thus, the LSD test effectively discriminated isolates that were different. These findings are important for future studies that analyze isolates with different characteristics and the relationship of these characteristics to the infectious process.
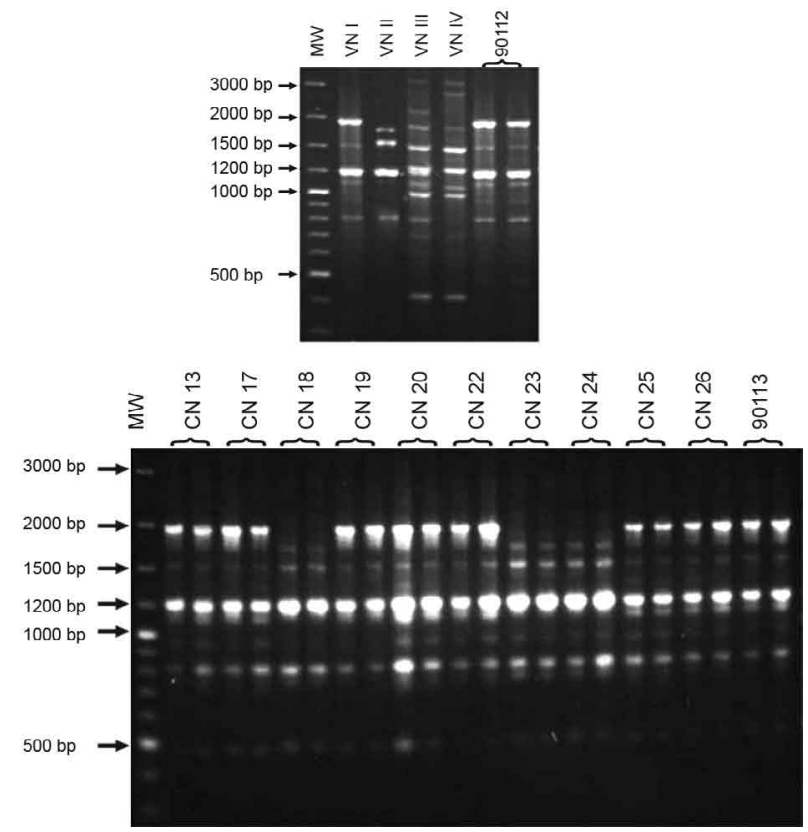

Fig. 2: agarose gel electrophoresis of amplified products by polymerase chain reaction-fingerprinting of Cryptococcus neoformans $(\mathrm{CN})$ isolates using $(\mathrm{GACA})_{4}$ microsatellite regions as probe. Upper gel: VNI, VNII, VNIII, VNIV molecular type controls and ATCC C. neoformans; below: the first and second Lanes of each pair correspond to strains before and after inoculation into animals, respectively. Left Lane shows molecular weight (MW) markers (100 bp DNA Ladder Plus, Fermentas). bp: base pairs. 
Of all isolates, $91 \%$ killed most experimental animals by day 24 postinfection. According to the data of Silva et al. (2006a), all strains studied that killed most animals in 24 days were considered highly virulent $(69 \%$ of 62 strains). Other reports have suggested that $C$. neoformans var. grubii serotype A and mating type $\alpha$ isolates are more virulent than serotype $\mathrm{D}$ and mating type a isolates (Barchiesi et al. 2005). As expected, virulence was confirmed in the isolates in our study, but the variability in hypo and hypervirulence was intriguing and should be further investigated.

In vitro virulence factors, fluconazole MICs and molecular profiles were not strongly associated with the virulence in animals, suggesting the involvement of other factors. Several studies that have found an association between in vitro virulence and pathogenicity in $C$. neoformans emphasize that virulence is a multifactorial characteristic; that is, if an isolate lacks one virulence factor, this lack could be compensated by the presence of another virulence factor (Barchiesi et al. 2005, McClelland et al. 2005, Clancy et al. 2006). It has been agreed upon that the production and thickness of the capsule are important, although in some reports, thickness was the more important factor (Clancy et al. 2006) and, in others, it was not (McClelland et al. 2005). It is widely accepted that capsule thickness depends on growth con-

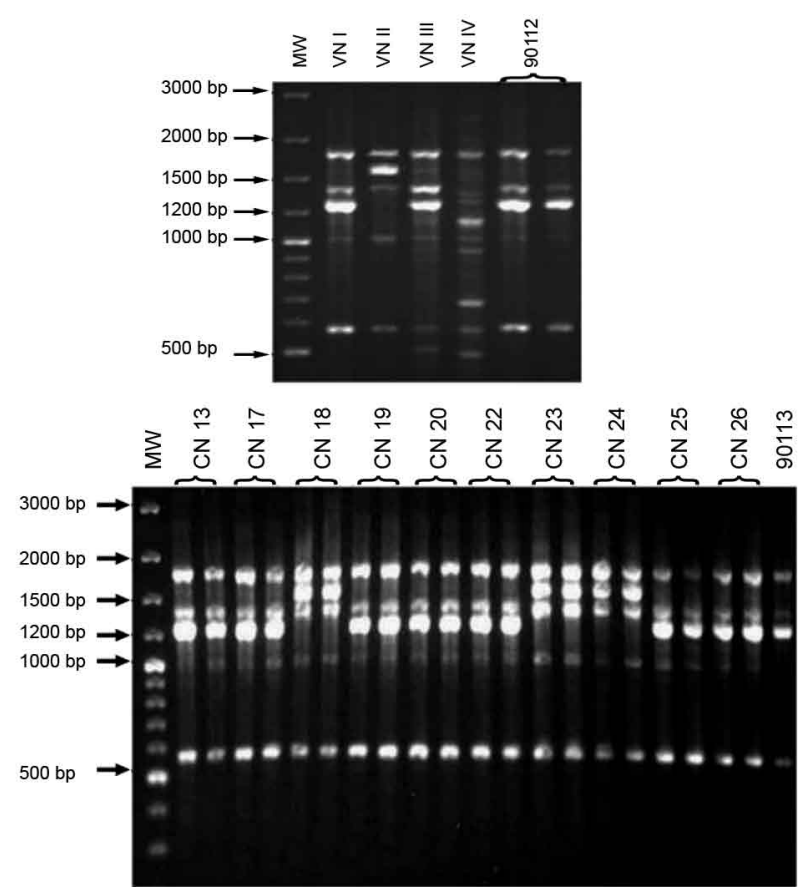

Fig. 3: agarose gel electrophoresis of amplified products by polymerase chain reaction-fingerprinting of Cryptococcus neoformans (CN) using M13 minisatellite regions as probe. Upper gel: VNI, VNII, VNIII, VNIV molecular type controls and ATCC C. neoformans; below: the first and second Lanes of each pair correspond to strains before and after inoculation into animals, respectively. Left Lane shows molecular weight (MW) markers (100 bp DNA Ladder Plus, Fermentas). bp: base pairs. ditions and on the organ affected, with the capsule being thicker in the lungs (Zaragoza et al. 2009). Microevolution occurring during infection has been demonstrated to influence capsule size (Rivera et al. 1998). A recent review about this virulence factor sheds light on many obscure points, thus opening ways to new investigations in this field (Zaragoza et al. 2009).

It is also possible that limitations in the sensitivity and specificity of the detecting methods have precluded reliable quantification of virulence factors and discrimination of isolates. Some authors have suggested that rate of growth influences pathogenicity by increasing the number of microorganisms in the infected organ or the quantity of metabolites liberated (Clancy et al. 2006).

Regarding the molecular types, the isolates studied were VNI (7 isolates) and VNII (3 isolates). According to recent studies, the VNI is the type most common in clinical and environmental isolates in different regions of Brazil, with a prevalence ranging from $64-95.7 \%$ (Matsumoto et al. 2007, Trilles et al. 2008, Mora et al. 2010).

In this study, most isolates of $C$. neoformans recovered from animals did not show differences with respect to either phenotypic or molecular characteristics when compared to the prepassaged lines. Although this result demonstrated that animal passage did not change the features involved, it is possible that the time period (7 days) was insufficient for microevolution. According to several studies, microevolution occurred over longer periods of time and after several passages, as an adaptation to the host (Currie et al. 1995, Franzot et al. 1998, Blasi et al. 2001, McClelland et al. 2005, Clancy et al. 2006, Almeida et al. 2007, Cavalcante et al. 2007). One exception occurred with urease. Urease activity is an important virulence factor for dissemination and invasion and it was detected by $24 \mathrm{~h}$ only in the postpassaged line, demonstrating that a change in the environment led to changes in the expression of this virulence factor.

Regarding in vitro resistance to fluconazole, resistance was not detected in any of the isolates, but there were changes in the MIC of one dilution for six isolates; we do not consider this change to be substantial, according to literature data. Some authors have suggested that the MIC is related to virulence (Iwata et al. 1990, Clancy et al. 2006) and it changes after passage of the yeast in animals (Currie et al. 1995, Silva et al. 2006b). Currie et al. (1995) showed a four-fold MIC increase for amphotericin B and one to three-fold increase for fluconazole after passage of isolates in animals, although statistical analysis showed that only the amphotericin results were significant. On the other hand, Silva et al. (2006b) did not find differences in susceptibility to fluconazole or amphotericin after animal infection. Studies should be conducted with a larger number of isolates to clarify these contradicting results and to better understand the in vivo and in vitro susceptibilities of to C. neoformans antifungal drugs.

In the current study, it was not possible to determine if any one of the virulence factors studied had a stronger influence on pathogenicity or on tissue yeast burden than the other virulence factors. No genetic variation between pre and postpassaged lines was detected by the methodology applied. However, temporal differences 
were demonstrated by the statistical tests with respect to the yeast burden in the brains of infected animals, but not in lungs. The isolates also showed large differences from one another, especially in lung yeast burden, as revealed by a multiple comparisons procedure. New studies of the factors related to $C$. neoformans virulence are necessary to develop new strategies to prevent and treat C. neoformans infections.

\section{ACKNOWLEDGEMENTS}

To CNPq, Brazil, for the Doctorate Fellowship received by Reginaldo dos Santos Pedroso, to Rodrigo Anselmo Cazzaniga, Rosymar Coutinho de Lucas, Solange Aparecida Fernandes Bocardo and Ludmilla Tonani, for valuable help in animal experiments, and to Dr Joseph Heitman of Duke University Medical Center, USA, for the provision of reference strains for molecular typing.

\section{REFERENCES}

Almeida AM, Matsumoto MT, Baeza LC, de Oliveira e Silva RB, Kleiner AA, Melhem M de S, Mendes Giannini MJ, Laboratory Group on Cryptococcosis 2007. Molecular typing and antifungal susceptibility of clinical sequential isolates of Cryptococcus neoformans from São Paulo State, Brazil. FEMS Yeast Res 7: 152-164.

Aoki S, Ito-Kuwa S, Nakamura K, Kato J, Ninomiya K, Vidotto V 1994. Extracellular proteolytic activity of Cryptococcus neoformans. Mycopathologia 128: 143-150.

Barchiesi F, Cogliati M, Esposto MC, Spreghini E, Schimizzi AM, Wickes BL, Scalise G, Viviani MA 2005. Comparative analysis of pathogenicity of Cryptococcus neoformans serotypes A, $\mathrm{D}$ and $\mathrm{AD}$ in murine cryptococcosis. J Infect 51: 10-16.

Blasi E, Brozzetti A, Francisci D, Neglia R, Cardinali G, Bistoni F, Vidotto V, Baldelli F 2001. Evidence of microevolution in a clinical case of recurrent Cryptococcus neoformans meningoencephalitis. Eur J Clin Microbiol Infect Dis 20: 535-543.

Bolano A, Stinchi S, Preziosi R, Bistoni F, Allegrucci M, Baldelli F, Martini A, Cardinali G 2001. Rapid methods to extract DNA and RNA from Cryptococcus neoformans. FEMS Yeast Res 1: 221-224.

Campbell LT, Carter DA 2006. Looking for sex in the fungal pathogens Cryptococcus neoformans and Cryptococcus gattii. FEMS Yeast Res 6: 588-598.

Casadevall A, Perfect JR 1998. Cryptococcus neoformans, ASM Press, Washington, $541 \mathrm{pp}$.

Cavalcante SC, Freitas RS, Vidal MSM, Dantas KC, Levi JE, Martins JEC 2007. Evaluation of phenotypic and genotypic alterations induced by long periods of subculturing of Cryptococcus neoformans strains. Mem Inst Oswaldo Cruz 102: 41-47.

Clancy CJ, Nguyen MH, Alandoerffer R, Cheng S, Iczkowski K, Richardson M, Graybill JR 2006. Cryptococcus neoformans var. grubii isolates recovered from persons with AIDS demonstrate a wide range of virulence during murine meningoencephalitis that correlates with the expression of certain virulence factors. Microbiology 152: 2247-2255.

CLSI/NCCLS - Clinical and Laboratory Standards Institute/National Commitee for Clinical Laboratory Standards 2002. Reference method for broth dilution antifungal susceptibility testing of yeasts. Approved standards. Document M27-A2. Clinical and Laboratory Standard Institute 22: 1-30.
Currie B, Sanati H, Ibrahim AS, Edwards JE Jr, Casadevall A, Ghannoum MA 1995. Sterol compositions and susceptibilities to amphotericin B of environmental Cryptococcus neoformans isolates are changed by murine passage. Antimicrob Agents Chemother 39: 1934-1937.

Echeverría A, Durante AG, Arechaval A, Negroni R 2002. Comparative study of two culture media for the detection of phospholipase activity of Candida albicans and Cryptococcus neoformans strains. Rev Iberoam Micol 19: 95-98.

Figueiredo TP 2007. Characterization of Cryptococcus strains isolated from AIDS patients: antifungal susceptibility, genotyping, and serotypes and mating types molecular determination, MSc Thesis, University of São Paulo, Ribeirão Preto, 99 pp.

Franzot SP, Mukherjee J, Cherniak R, Chen LC, Hamdan JS, Casadevall A 1998. Microevolution of a standard strain of Cryptococcus neoformans resulting in differences in virulence and other phenotypes. Infect Immun 66: 89-97.

Idnurm A, Bahn YS, Nielsen K, Lin X, Fraser JA, Heitman J 2005. Deciphering the model pathogenic fungus Cryptococcus neoformans. Nat Rev Microbiol 3: 753-764.

Iwata K, Yamashita T, Ohsumi M, Baba M, Naito N, Taki A, Yamada N 1990. Comparative morphological and biological studies on the itraconazole- and ketoconazole-resistant mutants of Cryptococcus neoformans. J Med Vet Mycol 28: 77-90.

Kozel TR 1995. Virulence factors of Cryptococcus neoformans. Trends Microbiol 3: 295-299.

Li YL, Leaw SN, Chen JH, Chang HC, Chang TC 2003. Rapid identification of yeasts commonly found in positive blood cultures by amplification of the internal transcribed spacer regions 1 and 2. Eur J Clin Microbiol Infect Dis 22: 693-696.

Matsumoto MT, Fusco-Almeida AM, Baeza LC, Melhem M de S, Mendes-Giannini MJ 2007. Genotyping, serotyping and determination of mating-type of Cryptococcus neoformans clinical isolates from São Paulo State, Brazil. Rev Inst Med Trop Sao Paulo 49: 41-47.

McClelland EE, Perrine WT, Potts WK, Casadevall A 2005. Relationship of virulence factor expression to evolved virulence in mouse-passaged Cryptococcus neoformans lines. Infect Immun 73: 7047-7050.

McPherson G 1990. Statistics in scientific investigation: its basis, application, and interpretation, Springer-Verlag, New York, $666 \mathrm{pp}$.

Meyer W, Castañeda A, Jackson S, Huynh M, Castañeda E, IberoAmerican Cryptococcal Study Group 2003. Molecular typing of IberoAmerican Cryptococcus neoformans isolates. Emerg Infect Dis 9: 189-195.

Meyer W, Mitchell TG 1995. Polymerase chain reaction fingerprinting in fungi using single primers specific to minisatellites and simple repetitive DNA sequences: strain variation in Cryptococcus neoformans. Electrophoresis 16: 1648-1656.

Meyer W, Mitchell TG, Freedman EZ, Vilgalys R 1993. Hybridization probes for conventional DNA fingerprinting used as single primers in the polymerase chain reaction to distinguish strains of Cryptococcus neoformans. J Clin Microbiol 31: 2274-2280.

Mora DJ, Pedrosa AL, Rodrigues V, Leite Maffei CM, Trilles L, dos Santos Lazéra M, Silva-Vergara ML 2010. Genotype and mating type distribution within clinical Cryptococcus neo- 
formans and Cryptococcus gattii isolates from patients with cryptococcal meningitis in Uberaba, Minas Gerais, Brazil. Med Mycol 48: 561-569.

Okabayashi K, Kano R, Watanabe T, Hasegawa A 2006. Serotypes and mating types of clinical isolates from feline cryptococcosis in Japan. J Vet Med Sci 68: 91-94.

Pedroso RS, Ferreira JC, Candido RC 2009a. The isolation and characterization of virulence factors of Cryptococcus spp from saprophytic sources in the city of Ribeirão Preto, São Paulo, Brazil. Microbiol Res 164: 221-227.

Pedroso RS, Ferreira JC, Lavrador MA, Maffei CM, Candido RC 2009b. Evaluation of the experimental inoculation of Cryptococcus albidus and Cryptococcus laurentii in normal mice: virulence factors and molecular profile before and after animal passage. Mycopathologia 168: 59-72.

Rivera J, Feldmesser M, Cammer M, Casadevall A 1998. Organdependent variation of capsule thickness in Cryptococcus neoformans during experimental murine infection. Infect Immun 66: 5027-5030.
Silva EG, Baroni F de A, Viani FC, Ruiz L da S, Gandra RF, Auler ME, Dias AL, Gambale W, Paula CR 2006a. Virulence profile of strains of Cryptococcus neoformans var. grubii evaluated by experimental infection in BALB/c mice and correlation with exoenzyme activity. J Med Microbiol 55: 139-142.

Silva EG, Paula CR, Baroni FA, Cury AE, Viani FC, Auler ME, Dias ALT, Ruiz LS, Matsumoto FE, Gambale V 2006b. Susceptibility to antifungal agents of Cryptococcus neoformans: evaluation before and after experimental infection in mice. In 16th Congress of the International Society for Human and Animal Mycology, June 25-29, Annals of the Congress, Paris, p. 82.

Trilles L, Lazéra MS, Wanke B, Oliveira RV, Barbosa GG, Nishikawa MM, Morales BP, Meyer W 2008. Regional pattern of the molecular types of Cryptococcus neoformans and Cryptococcus gattii in Brazil. Mem Inst Oswaldo Cruz 103: 455-462.

Zaragoza O, Rodrigues ML, De Jesus M, Frases S, Dadachova E, Casadevall A 2009. The capsule of the fungal pathogen Cryptococcus neoformans. Adv Appl Microbiol 68: 133-216. 